\section{Continuous axillary brachial plexus block for remission of sub-acute herpetic neuralgia}

\section{Binay Kumar Biswas, Samarjit Dey ${ }^{1}$, Sreyashi Sen ${ }^{2}$}

There exist very few options to prevent development of post-herpetic neuralgia (PHN) from sub-acute herpetic neuralgia $(\mathrm{SHN})$ state in patients where medications and/ or natural course of disease have failed to bring relief of acute herpetic pain. ${ }^{[1-3]}$ Conceptualized on neuropathic pain research, ${ }^{[4,5]}$ we had applied continuous brachial plexus block in such a patient and found complete remission of sub-acute herpetic pain. We intend to widely spread this striking concept among the readers for low cost treatment of sub-acute herpetic pain in difficult situation.

A 63-year-old lady ( $55 \mathrm{~kg}$ ) having thyromegaly (10 years) and uncontrolled hyperthyroidism presented with constant burning to shooting pain over outer aspect of left forearm and hand where she had developed painful skin eruptions 10 weeks back. Considering it as herpes zoster, patient had already been treated with various NSAIDs and neuropathic pain medications by primary physician. Later on, patient was referred to pain clinic where we found her to have - SHN ((Numeric Rating Scale/NRS -9/10) affecting areas mostly supplied by radial nerve (C5-C6-C7 distribution) with allodynia and hyperalgesia in the affected areas. Considering the severity, trend and duration of pain as well as her age, we anticipated least possibility of its natural remission any more. We planned for continuous brachial plexus block through axillary route with catheter placement targeting blockade of painful volley of afferent inputs from sensitized receptors to alleviate the agony as well as to halt the progress of the disease, if possible, towards its development of PHN. With a 22G insulated needle (Centiplex: B-Braun, Germany) and nerve stimulator (EZSTIM 2, Model 400; Life Tech Company, USA), left-sided axillary brachial plexus block was accomplished under sterile condition. The needle was placed superior to the axillary artery (with an aim to place the catheter posterior to artery predominantly occupied by radial nerve) and needle advancement was adjusted to best stimulator response (metacarpo-phalangeal as well as wrist extension) with $<0.4 \mathrm{~mA}$ current. Once

Department of Anesthesiology, Employees State Insurance-Post Graduate Institute of Medical Sciences and Research, Manicktala, Kolkata, West Bengal, ${ }^{1}$ Department of Anesthesiology, North Eastern Indira Gandhi Regional Institute of Health and Medical Sciences, Shillong, Meghalaya, ${ }^{2}$ Department of Anesthesiology, Medical College, Kolkata, West Bengal, India 


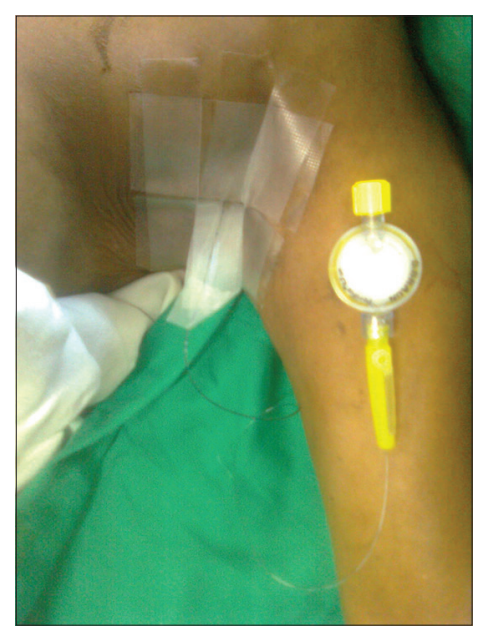

Figure 1: Placement of axillary brachial plexus catheter

correct needle placement obtained, catheter was placed $5 \mathrm{~cm}$ further in and was fixed securely. No vascular complication noticed [Figure 1]. Total $30 \mathrm{ml}$ of $0.25 \%$ bupivacaine was administered through catheter. Sensory block over the area supplied predominantly by radial and median nerve developed within 15 minutes. Immediately, patient's NRS came down to 4/10. Allodynia was reduced. With reassurance, we re-started gabapentin $300 \mathrm{mg} /$ day. After 4 hours, infusion of $0.25 \%$ bupivacaine ( $8 \mathrm{ml} /$ hour) was started and continued for 24 hours followed by $0.125 \%$ for next 48 hours. From the third day onwards, infusion was stopped intermittently and re-started again depending on pain intensity. On seventh day, pain score was $2 / 10$, allodynia abolished; however, hyperalgesia continued with lesser intensity. Pain score was found to be 2-3/10 with improvement of hyperalgesia on the eighth day. Gabapentin was increased to 900/day, oral tramadol $50 \mathrm{mg} /$ day was initiated and infusion of bupivacaine was stopped. On day 9, pain score did not change and catheter was removed. On day 10 , the patient was discharged to home with advice to continue oral medications. Follow up on $15^{\text {th }}$ day revealed no constant pain but occasional tingling in left forearm. Tramadol was stopped; gabapentin $900 \mathrm{mg}$ / day continued for three months. After three months, she had no pain; however, had relative numbness over dorsal aspect of left forearm. Medication was gradually weaned off over a period of six months. Patient was pain free thereafter till $18^{\text {th }}$ months of follow up with partial improvements of numbness.

Acute herpetic pain, instead of complete remission may pass to SHN phase with a tendency to its ultimate development of PHN producing severe impact on personal, occupational and social life. ${ }^{[6]}$ Active interventions to stop progression of SHN phase are key factors to prevent the development of PHN. In herpetic infection, direct neurolytic effect of virus and associated inflammation destruct $C$ receptors producing constant burning pain whereas, breaches in axonal membrane may generate short circuit like discharge of nerve impulse (injury discharge) producing sharp intermittent shooting pain. ${ }^{[7]} \mathrm{New}$ sprouts from $A ß$ fibres and remaining $C$ receptors produce abnormal neuronal networks. ${ }^{[4]}$ This aberrant network and sensitised nociceptors (mediated by inflammatory noxious substances like leukotriene, bradykinin, etc.) have lower activation threshold for stimulation..$^{[5]}$ Therefore, it can not only be stimulated by normally innocuous stimuli leading to development of allodynia, but may also has increased response to stimuli that are more intense than normal threshold leading to development of various types of hyperalgesia. ${ }^{[4,7,8]}$ This heralds the development of neuropathic pain. This is often further facilitated by recruitment of sympathetic nervous system with the newly regenerated neuronal network at the epidermal level. ${ }^{[7]}$

Our patient had allodynia as well as hyperalgesia and there might have been early subclinical involvement of sympathetic system too favouring its transition to continuation of neuropathic pain state instead of remission. Upon continual stimulation from peripheral sensitization, voltage-mediated glutamate-dependent N-methyl-Daspartate receptor (NMDA) receptors at lamina I, V and wide dynamic range neuron of spinal cord get activated producing rapid, spontaneous and independent firing of spinal neurons ('wind up' phenomenon). ${ }^{[9,10]}$ These along with prolonged inflammatory reaction at dorsal root ganglion (DRG) by replicating virus have the potential to produce transcription-dependent sensitization and irreversible structural modifications in various areas of $\mathrm{CNS}$ leading to the development of chronic neuropathic pain. ${ }^{[11]}$ Continuation of hyperalgesia, pain and deterioration of its intensity in our patient might have also been due to similar recruitment of central pain producing mechanism. ${ }^{[9]}$

Our intervention of continuously blocking the afferent volley of painful impulses to CNS, most probably, could prevent establishment of irreparable changes in nervous system, thereby bringing back the normalcy in its function instead of development of a state of chronic neuropathic pain. Block mediated strong suppression of painful afferent inputs not only prevented the progression of central and peripheral sensitization but also might have helped re-establishment of impaired balance between excitatory and inhibitory mechanism in sensitized dorsal horn neurons. ${ }^{[12]}$ Early institution of stronger distal sympathetic block (axillary block is twice stronger than stellate ganglion block for distal upper extremity sympatholysis) might have re-established the blood supply in the affected neuronal tissue helping her to achieve a complete recovery of pain. ${ }^{[13]}$ Virus-induced inflammation causes loss of epidermal nerve fibres. ${ }^{[1,7]}$ Our patient's numbness in hand might have been because of damaged epidermal nerves in the affected area. Axillary brachial plexus block possesses lesser chances for development of complications as compared to cervical epidural or stellate ganglion block (especially in a patient 
with thyromegaly). We emphasize that because of being easier to institute with better safety profile and cheaper in cost relative to other interventions, continuous axillary block along with oral medication may be advocated for remission sub-acute herpetic neuralgia involving upper extremity.

\section{REFERENCES}

1. Thyregod HG, Rowbotham MC, Peters M, Possehn J, Berro M, Petterson KL. Natural history of pain following herpes zoster. Pain 2007;128:148-56.

2. Iseki M, Morita Y, Nakamura Y, Ifuku M, Komatsu M. Efficacy of limited-duration spinal cord stimulation for subacute post herpetic neuralgia. Ann Acad Med Singapore 2009;38:1004-6.

3. Harke H, Gretenkort P, Ladleif HU, Koester P, Rahaman S. Spinal cord stimulation in postherpetic neuralgia and in acute herpes zoster pain. Anesth Analg 2002;94:694-700.

4. Fields HL, Rowbotham M, Baron R. Postherpetic neuralgia: Irritable nociceptors and deafferentation. Neurobiol Dis 1998;5:209-27.

5. Funk CD. Prostaglandins and leukotrienes: Advances in eicosanoid biology. Science 2001;294:1871-5.

6. Christo PJ, Hobelmann G, Maine DN. Post herpetic neuralgia in older adults: Evidence-based approaches to clinical management. Drugs Aging 2007;24:1-19.

7. Bennet GJ, Watson CP. Herpes zoster and post neuralgia: Past, present and future. Pain Res Manage 2009;23:275-83.

8. Woolf CJ, Shortland P, Coggeshall RE. Peripheral nerve injury triggers central sprouting of myelinated afferents. Nature 1992;355:75-8.
9. Woolf CJ, Salter MW. Neuronal plasticity: Increasing the gain in pain. Science 2000;288:1765-9.

10. Ji RR, Kohno T, Moore KA, Woolf CJ. Central sensitization and LTP: Do pain and memory share similar mechanisms? Trends Neurosci 2003;26:696-705.

11. Staud R, Cannon RC, Mauderli AP, Robinson ME, Price DD, Vierck CJ Jr. Temporal summation of pain from mechanical stimulation of muscle tissue in normal controls and subjects with fibromyalgia syndrome. Pain 2003;102:87-95.

12. Mizuno J, Sujimoto S, Ikeda M, Kamakura T, Machida K, Kusume S. Treatment with stellate ganglion block, continuous epidural block and ulnar nerve block of a patient with postherpetic neuralgia who developed complex regional pain syndrome (CRPS) Masui 2001;50:538-51.

13. Winnie AP, Hartwell PW. Relationship between time of treatment of acute herpes zoster with sympathetic blockade and prevention of post-herpetic neuralgia: Clinical support for a new theory of the mechanism by which sympathetic blockade provides therapeutic benefit. Reg Anesth 1993;18:277-82.

\begin{tabular}{|l|l|}
\hline \multicolumn{2}{|c|}{ Access this article online } \\
\hline Quick Response Code: & Website: \\
\hline & www.jnaccjournal.org \\
\cline { 2 - 3 } & \\
\hline & \\
\hline
\end{tabular}

